\title{
The Synchytrium endobioticum AvrSen1 Triggers a Hypersensitive Response in Sen1 Potatoes While Natural Variants Evade Detection
}

\author{
Bart T. L. H. van de Vossenberg, ${ }^{1,2}$ Charlotte Prodhomme, ${ }^{3}$ Gert van Arkel, ${ }^{3}$ Marga P. E. van \\ Gent-Pelzer, ${ }^{1}$ Marjan Bergervoet, ${ }^{3}$ Balázs Brankovics, ${ }^{1}$ Jarosław Przetakiewicz, ${ }^{4}$ Richard G. F. Visser, ${ }^{3}$ \\ Theo A. J. van der Lee, ${ }^{1}$ and Jack H. Vossen ${ }^{3,+}$ \\ ${ }^{1}$ Wageningen University and Research, Biointeractions and Plant Health, Droevendaalsesteeg 1, 6708 PB, Wageningen, The \\ Netherlands \\ ${ }^{2}$ Dutch National Plant Protection Organization, National Reference Centre, Geertjesweg 15, 6706EA, Wageningen, The \\ Netherlands \\ ${ }^{3}$ Wageningen University and Research, Plant Breeding \\ ${ }^{4}$ Plant Breeding and Acclimatization Institute, National Research Institute, Radzików, 05-870 Błonie, Warsaw, Poland
}

Accepted 22 June 2019.

\begin{abstract}
Synchytrium endobioticum is an obligate biotrophic fungus of division Chytridiomycota. It causes potato wart disease, has a worldwide quarantine status and is included on the Health and Human Services and United States Department of Agriculture Select Agent list. S. endobioticum isolates are grouped in pathotypes based on their ability to evade host resistance in a set of differential potato varieties. Thus far, 39 pathotypes are reported. A single dominant gene (Sen1) governs pathotype 1 (D1) resistance and we anticipated that the underlying molecular model would involve a pathogen effector (AvrSen1) that is recognized by the host. The $S$. endobioticum-specific secretome of 14 isolates representing six different pathotypes was screened for effectors specifically present in pathotype 1 (D1) isolates but absent in others. We identified a single AvrSen1 candidate. Expression of this candidate in potato Sen1 plants showed a specific hypersensitive response (HR), which cosegregated with the SenI resistance in potato populations. No HR was obtained with truncated genes found in pathotypes that evaded recognition by Sen1. These findings established that our candidate gene was indeed Avrsen1. The $S$. endobioticum AvrSen1 is a single-copy gene and encodes a 376-amino-acid protein without predicted function or functional domains, and is the first effector gene identified in Chytridiomycota, an extremely diverse yet underrepresented basal lineage of fungi.
\end{abstract}

${ }^{\dagger}$ Corresponding author: J. H. Vossen; jack.vossen@wur.nl

Funding: This research (TKI-TU 1406-056) is financially supported by the Dutch Topsector Horticulture \& Starting Materials. Within the Topsector, private industry, knowledge institutes, and the government are working together on innovations for sustainable production of safe and healthy food and the development of a healthy green environment.

*The $\boldsymbol{e}$-Xtra logo stands for "electronic extra" and indicates that seven supplementary figures and five supplementary tables are published online.

The author(s) declare no conflict of interest.

This article is in the public domain and not copyrightable. It may be freely reprinted with customary crediting of the source. The American Phytopathological Society, 2019.
Keywords: avirulence factors, cell death, Chytridiomycota, effector, fungus-plant interactions, genomics, hypersensitive response, metabolomics, plant-pathogen interaction, population genetics, proteomics, resistance genes

Potato wart is a severe disease of cultivated potatoes, caused by the soil borne obligate biotrophic fungus Synchytrium endobioticum (Schilb.) Percival. Hypertrophic growth of the infected tissue resulting in wart-like malformations that destroy the economic value of the potato tubers characterize the disease (Curtis 1921). Resting spores that are formed in the warted potato tissues can remain viable and infectious in soils for decades (Przetakiewicz 2015). No chemical control agents are available to eradicate the pathogen from contaminated soils (Hampson 1988), and disease management relies on preventing its introduction and spread through the deployment of resistant potato varieties. Because of its impact on potato cultivation, $S$. endobioticum has a quarantine status in most countries with potato production and is included on the Health and Human Services and United States Department of Agriculture Select Agent list (USDA CDC 2018). The pathogen has been reported in potato-growing countries in Asia, Africa, Europe, North America, South America, and Oceania (EPPO 2018).

Isolates of the pathogen are grouped into pathotypes based on their interaction with a differential set of resistant potato varieties (OEPP/EPPO 2017). For decades after the first description of the pathogen by Schilberszky (1896), only a single pathotype was recognized, which today is referred to as pathotype 1(D1). Emergence of a new pathotype, now known as 2(G1), was recognized when wart formation was discovered on formerly resistant potato cultivars in 1941 (Braun 1942). Currently, 39 pathotypes have been described, of which pathotypes 1(D1), 2(G1), 6(O1), and 18(T1) are most widespread in western Europe and considered to be of main importance (Baayen et al. 2006). Comparative analysis of $30 \mathrm{~S}$. endobioticum isolates using their mitochondrial genome sequences showed that the pathogen was introduced multiple times in Europe and, successively, several pathotypes emerged in parallel. Interestingly, single isolates were found to represent populations of distinct genotypes (van de Vossenberg et al. 2018). 
S. endobioticum belongs to the division Chytridiomycota, a basal lineage of fungi that are evolutionarily diverse and arose in the Mesoproterozoic Era approximately 1,000 to 1,600 million years ago (Heckman et al. 2001). Despite being ubiquitous in nature, only a few species of Chytridiomycota are studied at the molecular or genomic level. There are approximately 1,500 formally described chytrid species, and the genus Synchytrium alone contains over 200 described species, most of which are obligate biotrophic plant pathogens. S. endobioticum is one of the best studied members of Chytridiomycota but, thus far, studies on S. endobioticum focused on its life cycle, epidemiology, pest management, and molecular tools for detection (Hampson 1993; Obidiegwu et al. 2014). Little is known about the molecular mechanisms underlying the obligate biotrophic or pathogenic lifestyle of this pathogen. As with other species of Chytridiomycota, S. endobioticum does not form hyphae or mycelia but produces summer and resting sporangia that contain motile zoospores (Barr 2001; Karling 1964). Zoospores encyst on the potato host cell and the content of the spore penetrates the host cell, leaving the empty cyst wall outside the host. After penetration, the fungal thallus is separated from the point of infection and migrates to the host nucleus. The intracellular lifecycle is completed by forming summer sporangia, which give rise to new zoospores that either reinfect the host or conjugate to produce biflagellate zygotes that give rise to resting spores after host penetration (Curtis 1921; Lange and Olson 1981a,b). Even in incompatible interactions, zoospores have been reported to penetrate host cells, after which an immune response is triggered, resulting in a localized cell death (Cartwright 1926).

Plant-pathogen interactions have evolved over millions of years, generating a broad range of diversity on both sides of the interaction. The molecular mechanisms involved in plant-fungi interactions have been reviewed by various authors (Asai and Shirasu 2015; Cook et al. 2015; Lo Presti et al. 2015; Wang and Wang 2018). Weapons in this arms race are pathogen effector proteins and plant resistance $(R)$ genes. Pathogen genes coding for effectors that are recognized by a plant $R$ gene and trigger effector-triggered immunity are called avirulence $(A v r)$ genes. In agricultural systems, the arms race model (Dawkins et al. 1979), in which both the pathogen and the host develop in continuous cycles, causing temporary fixation of new effector and $R$ gene alleles, has been suggested to be the main driving force in pathogen effector and plant defense evolution (Brown and Tellier 2011).

Potato is host to many pathogens from diverse taxonomical groups such as oomycetes (e.g., Phytophthora infestans), bacteria (e.g., Ralstonia spp.), nematodes (e.g., Globodera spp.), and also viruses (e.g., Potato virus $Y$ ). Resistance in most pathosystems is governed by $R$ gene recognition of specific effector molecules. The best elaborated examples are the gene-for gene (Flor 1971) interactions in the P. infestans pathosystem (Haverkort et al. 2016). In potato, several quantitative resistance loci (QRLs) for S. endobioticum resistance have been identified, and two of these give resistance to pathotype 1(D1) isolates only: Senl (Hehl et al. 1999) and Sen1-4 (Brugmans et al. 2006), which reside on chromosomes 11 and 4, respectively. Recently, Sen 2 and Sen 3 were described, which give broad resistance to multiple pathotypes, including 1(D1) for Sen2 (Plich et al. 2018; Prodhomme et al. 2019).

The recently annotated genomes of the pathotype 1(D1) isolate MB42 (QEAN00000000 v.1) and pathotype 6(O1) isolate LEV6574 (QEAM00000000 v.1) (van de Vossenberg et al. 2019b) open up the possibility to identify Avr gene candidates using a comparative genomic approach. Availability of $S$. endobioticum Avr genes will greatly advance our understanding and management of this challenging obligate, biotrophic, soilborne, pathogenic fungus. Comparative studies of genome sequences from $S$. endobioticum isolates most frequently found in Europe and Canada revealed an AvrSenl gene candidate which was present in a single copy in pathotype 1(D1) genomes. The gene showed different variants in pathotypes that are not recognized by Sen1. This gene represents the first Avr gene reported from a pathogen in the fungal phylum of Chytridiomycota. We discuss the potential applications of the applied comparative genomic strategy and the identified AvrSen 1 gene for potato wart disease resistance and management.

\section{RESULTS}

\section{Screening for AvrSen1 candidates.}

Out of sequence data generated by van de Vossenberg et al. (2018), 14 isolates were selected because of their $>10 \times$ median sequence coverage and known pathotype identity (Supplementary Fig. S1). The S. endobioticum pathotype 1(D1) isolate MB42 genome contains 8,031 protein-coding genes, of which $477(5.9 \%)$ were regarded as the MB42 secretome due to the presence of a signal peptide and absence of transmembrane domains or GPI anchors. Almost two-thirds of the secretome $(n$ $=304,64 \%$ ) consists of species-specific genes (Supplementary Table S3).

To determine polymorphisms at the encoded protein sequence level (loss of function) and the DNA level (gene loss), reads of the 14 isolates were mapped to all nuclear genome scaffolds of pathotype 1(D1) isolate MB42. For the different isolates, nonsynonymous $(\mathrm{dN})$ substitutions were observed in 171 to 1,126 gene models at a minimal frequency of $70 \%$ (Supplementary Table S4). Pathotype 8(F1), 18(T1), and 38(N1) isolates had significantly higher numbers of genes with $\mathrm{dN}$ substitutions (general analysis of variance, $P<0.001$ ). From the structural absence analysis of the different isolates, 41 to 206 gene models had $<90 \%$ coverage relative to the MB42 reference genome and were predicted to be structurally absent.

Five gene models showed the hypothesized AvrSen 1 pattern; that is, present in pathotype 1(D1) isolates and absent in the higher pathotypes. Four of these genes were species specific and only one belonged to the secretome (Fig. 1). After manual verification of gene prediction, functional annotations, and weighing of the significance of polymorphisms (i.e., leading to conservative or nonconservative $\mathrm{dN}$ substitutions), only a single gene remained as an AvrSen1 candidate: SeMB42_g04087. As opposed to the other genes with the hypothesized AvrSenl pattern, all polymorphisms in SeMB42_g04087 led to the introduction of stop codons, resulting in truncated gene models.

Gene SeMB42_g04087 is unique to S. endobioticum genomes; even in the closely related species $S$. microbalum, no orthologs were found. The gene is 1,360 nucleotides (nt) long, consists of four exons and three introns, and encodes a 376amino-acid protein containing a signal peptide with cleavage site at amino acid position 30 . No predicted functions, transmembrane domains, or other functional annotations such as nuclear localization signals, chloroplast targeting peptides, or mitochondrial targeting peptides were identified. The protein contains two cysteine residues and, compared with the entire S. endobioticum MB42 proteome, it has a relatively high percentage of tyrosine residues (MB42 proteome: 2.8\%; SeMB42_g04087: 5.1\%), whereas other amino acid residues show more average frequencies.

\section{AvrSen1 and its variants.}

The candidate AvrSenl gene was found to be present in the two pathotype 1(D1) isolates and structurally absent in one of two pathotype 2(G1) isolates (i.e., MB08) and in both 
pathotype 18(T1) isolates (Fig. 2). In the other isolates, two forms of functional absence were observed: a $\mathrm{G}$ insertion at position 769 of the coding sequence (CDS) causing a frameshift, thereby introducing a stop codon at position 256 of the amino acid sequence (avrSen1: $\mathrm{Asp}^{256}>$ stop $^{256}$ ); and a C > T substitution at position 916 of the CDS causing the introduction of a stop codon at position 306 of the amino acid sequence (avrSen1:Gln ${ }^{306}>$ stop $^{306}$ ). avrSen1: Asp $^{256}>$ stop $^{256}$ and avrSen $1: \mathrm{Gln}^{306}>$ stop $^{306}$ are referred to as variant 1 and variant 2 , respectively (Fig. 2). Variant 1 was detected in pathotype 2(G1) isolate SE4, 6(O1) isolates SE5 and SE6, $8(\mathrm{~F} 1)$ isolate DEN01, and 38(N1) isolate MB56. Variant 2 was exclusively found in the Canadian pathotype 6(O1) isolates LEV6574, LEV6602, LEV6687, and LEV6748. Also, two forms of structural absence were identified: a deletion ranging from position 29,142 to 30,137 (SeMB42scf158 $\Delta 29,142$ $30,137)$, which was found in the two pathotype 18(T1) isolates (MB17 and SE7), and a deletion found only in one pathotype 2(G1) isolate (MB08) (SeMB42scf158_28,298-30,137). These two forms of structural absence are referred to as variants 3 and 4, respectively.

Mapping of RNAseq data obtained from infected plant parts reflects the variants identified with DNA-derived Illumina NGS data. Pathotype 1(D1) showed expression of the AvrSen1 gene, whereas tissues infected with pathotypes $2(\mathrm{G} 1)$ and $6(\mathrm{O} 1)$ from haplogroup 2 (Fig. 2) both showed the AvrSen1 variant 1-specific single nucleotide polymorphism (SNP). For both samples obtained from pathotype 18(T1)-infected plants, no expression of the AvrSenl gene was found, which is in line with the observed structural absence for this pathotype.

\section{Specific recognition of AvrSen1 in potato clones carrying the Sen1 locus.}

Eight progeny plants were selected from the Aventra $x$ Desiree and Aventra $\times$ Kuras crosses. Together with the parents of these populations, seven genotypes possessed the Sen1 markers and were resistant to S. endobioticum pathotype 1(D1), whereas the four remaining genotypes lacked the Sen1 markers and were susceptible to pathotype 1(D1). In total, 153 agroinfiltrations were performed with the AvrSen1 construct without signal peptide (AvrSen $1 \Delta \mathrm{SP})$ in four different experiments, 45 with the AvrSenl construct with signal peptide (AvrSen $1+\mathrm{SP}$ ) and 24 for each of the truncated variants without signal peptide (Supplementary Table S5). When plants possessing Sen 1 were agroinfiltrated with the AvrSen $1 \Delta$ SP construct, hypersensitive response (HR)-like cell death was visible in $95 \%$ of all infiltrated sites; this in contrast to agroinfiltration of AvrSen $1 \Delta \mathrm{SP}$ in plants lacking Sen1, where $98 \%$ produced no visible reaction. This clearly showed that AvrSen 1 was recognized in a Sen1-dependent way. Interestingly, the AvrSen $1+$ SP construct did not produce an HR in Sen1 plants, suggesting cytoplasmic recognition of the gene product. Also, both truncated variants avrSen $1: \mathrm{Asp}^{256}>$ stop $^{256}$ and avrSen 1 : $\mathrm{Gln}^{306}>$ stop $^{306}$ were not recognized by Senl plants and produced no visible reaction (Fig. 3).

\section{Presence of AvrSen1 and its variants in $S$. endobioticum isolates.}

The presence of the AvrSenl gene or its variants could be determined in 17 of $30 \mathrm{~S}$. endobioticum isolates sequenced by van de Vossenberg et al. (2018) by mapping of Illumina sequence reads to the MB42 genome. In addition, PacBio SMRT circular consensus sequence (CCS) reads generated from the AvrSen 1 amplicon allowed the detection of the AvrSen 1 gene or its variants for three additional isolates. In total, the major AvrSen1 variant was determined for 20 isolates and superimposed to the mitochondrial haplotype network that was previously generated (Fig. 4). Based on variation of the mitochondrial genome, $S$. endobioticum isolates clustered in four major groups (haplogroups), representing separate introductions from which pathotypes $2(\mathrm{G} 1)$ and $6(\mathrm{O} 1)$ emerged multiple times independently (van de Vossenberg et al. 2018).

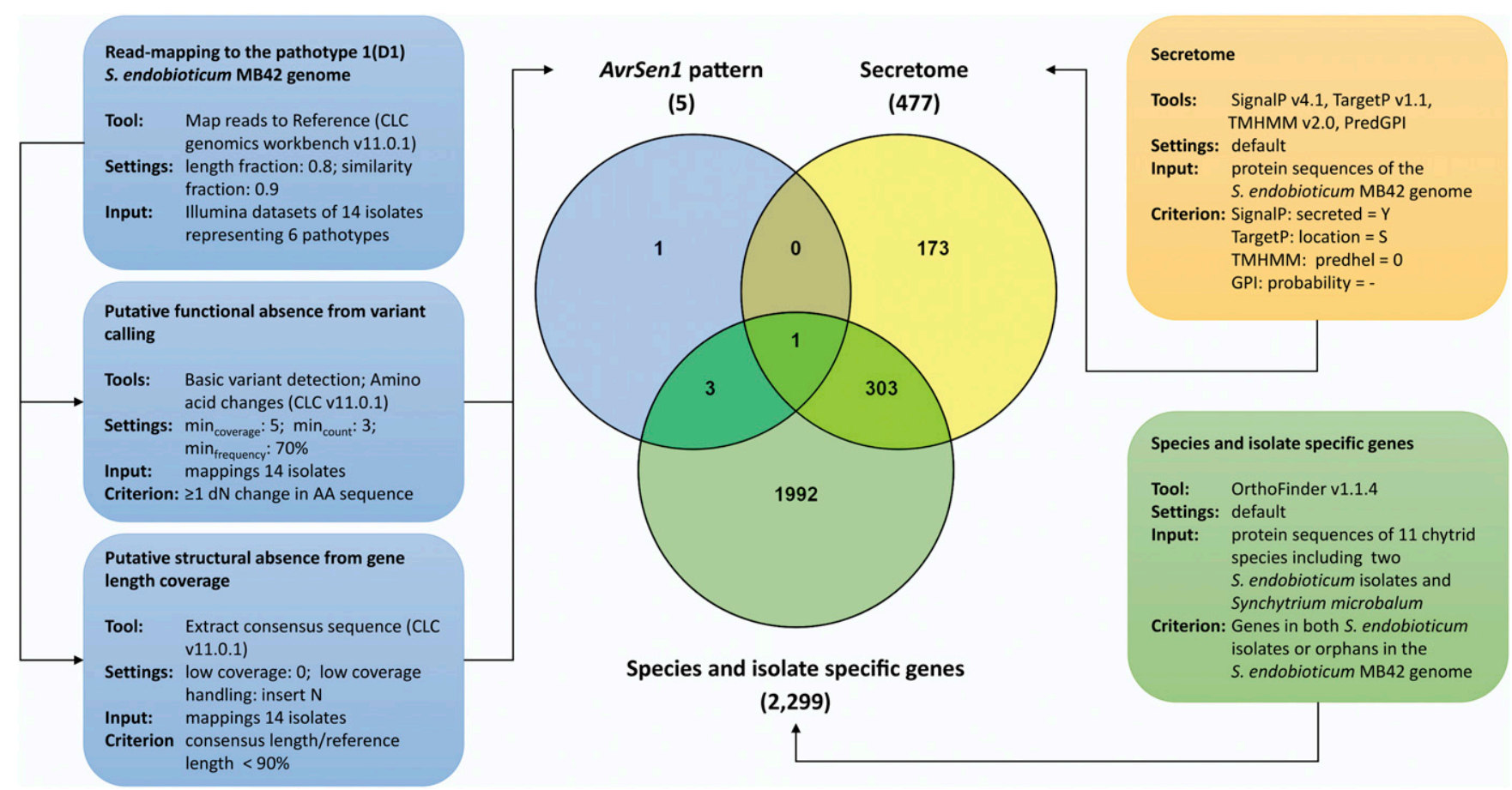

Fig. 1. Converging approaches for the identification of AvrSenl candidates. The pipeline contains three main elements indicated in blue (putative presence and absence of genes), yellow (determination of the secretome), and green (species and isolate specific genes). Bioinformatic tools, their settings, and input and output criteria are shown. Intersections of these three elements resulted in the identification of a single candidate AvrSen1 gene from a total of 8,031 genes. 
The AvrSenl gene was identified in pathotype 1(D1) isolates from The Netherlands (MB42 and NED1), the German pathotype 1(D1) isolate 01WS, and the Peruvian isolate without known pathotype identity. Variant 1 of AvrSen 1 was found most frequently among the remaining isolates, and was identified in haplogroups 1, 2, and 3. Interestingly, pathotype 6(O1) samples from Canada possess a different AvrSen1 variant compared with the European pathotype $6(\mathrm{O} 1)$ isolates (i.e., variant 2 versus variant 1 , respectively). Also, pathotype $2(\mathrm{G} 1)$ isolate MB08 from haplogroup 1 possesses a different variant compared with the pathotype $2(\mathrm{G} 1)$ isolates from haplogroup 2 (i.e., variant 4 compared with variant 1 , respectively).

\section{Cooccurrence of AvrSen1 and its variants within $S$. endobioticum isolates.}

Read mappings of several isolates generated for the identification of the AvrSenl candidates showed that the AvrSenl locus was polymorphic in some isolates, and low percentages of the AvrSen 1 wild type were present in these isolates. To further quantify the presence of AvrSenl and its variants within isolates, the gene was PCR amplified from genomic DNA (Fig. 5A and B) and subjected to PacBio SMRT sequencing, which produced 8,793 to $32,336 \mathrm{CCS}$ for the selected isolates (Supplementary Table S1). PacBio CCS reads were generated from a median number of 36 or 37 passages for all isolates included (Supplementary Fig. S3). In pathotype 1(D1) isolate MB42, all reads represented the AvrSenl wild type (Fig. 5C). PacBio SMRT sequencing confirmed the presence of variant 1 as the dominant haplotype in isolates SE4, SE5, SE6, and MB56 that were also included in the screening to identify AvrSen 1 candidates. In these isolates, representing three higher pathotypes, the $\mathrm{G}$ insertion at position 769 of the CDS was observed in $93 \%$ of all reads. Interestingly, the AvrSen1 haplotype was also found in these samples, with $7 \%$ of the reads lacking the insertion that leads to the truncation of the gene. Pathotype $2(\mathrm{G} 1)$ isolate $02 \mathrm{WS}$, which was not included in the screening for AvrSenl candidates because a lack of read coverage, showed the presence of the AvrSenl variant 1 insertion in similar percentages $(92 \%)$ as the other isolates carrying the AvrSenl variant 1 sequenced with PacBio.

In addition to the reads mapping to the MB42 genomic scaffold containing AvrSen 1, low numbers (1 to 57) of small (95 to $640 \mathrm{nt}) \mathrm{CCS}$ reads were obtained for the tested isolates. In many cases, these small CCS reads could be identified as nonspecific amplification of bacteria or potato. However, a particular 466- to 470-bp amplicon representing a deletion variant was found to be present in six of the analyzed isolates in 2 to 5 copies/isolate (on average, 1.6 in 10,000 reads) (Supplementary Fig. S4). The short sequences resemble the AvrSen1 variant 3 deletion, and were found in both 1(D1) isolates, both 2(G1) isolates, and the 6(O1) isolates SE5 and SE6. The short sequence was not identified in $38(\mathrm{~N} 1)$ isolate MB56 or in $6(\mathrm{O} 1)$ isolate $\mathrm{E} / \mathrm{II} / 2015$.

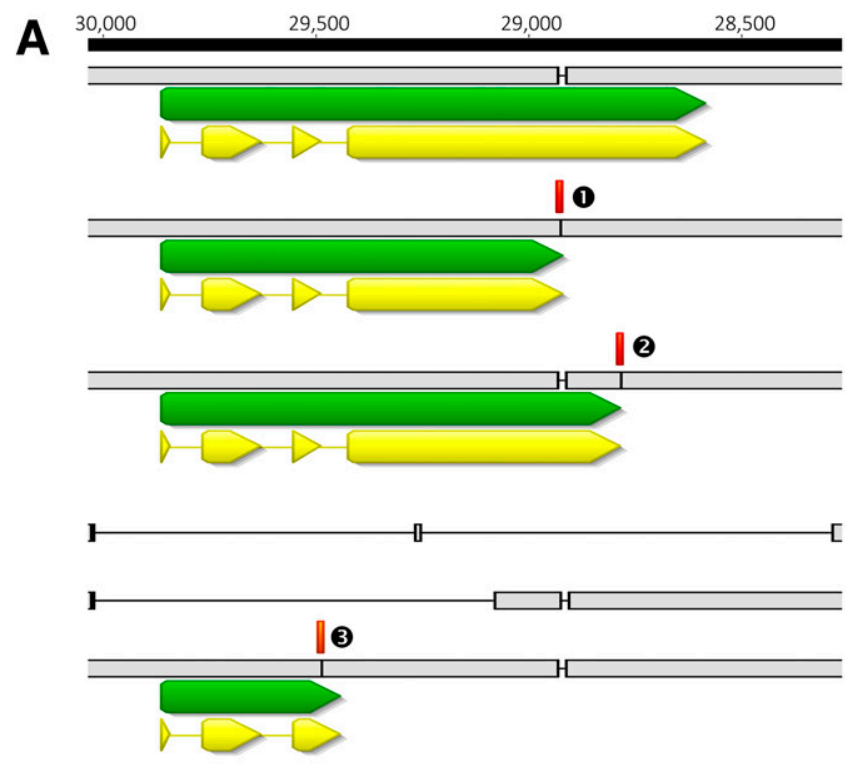

\section{AvrSen1}

avrSen1:Asp $256>$ stop $^{256}$

(variant 1)

avrSen1:Gln ${ }^{306}>$ stop $^{306}$

(variant 2)

SeMB42scf158 $\Delta 29,142-30,137$

(variant 3)

SeMB42scf158 $\Delta 28,298-30,137$

(variant 4)

avrSen1:Asp ${ }^{94}>$ stop $^{94}$

(variant 5)

B

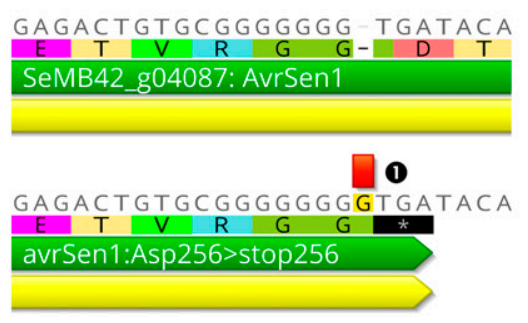

C

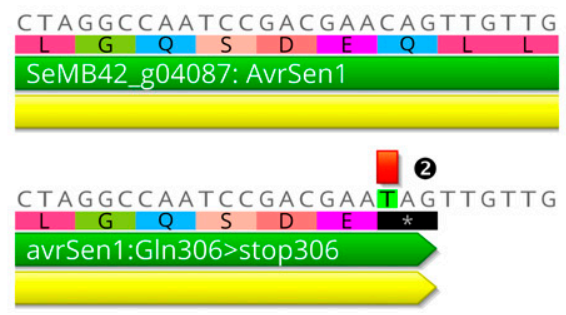

D

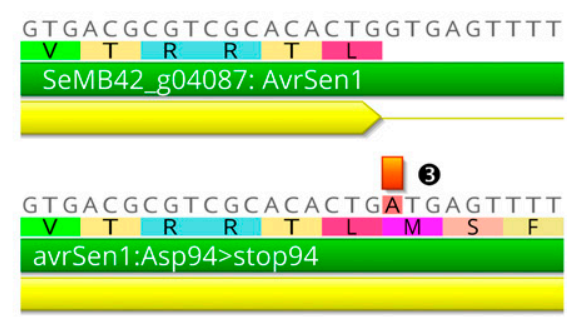

Fig. 2. AvrSen1 gene and its variants. A, Sequences identical to the MB42 AvrSenl gene are presented in light gray, and variants to the AvrSenl gene are annotated in red (1,2, and 3 for the truncated variants). Gene annotation and coding sequence (CDS) annotation are in green and yellow, respectively. B, Detail of the $\mathrm{G}$ insertion in the genomic sequence of variant 1 isolates relative to isolate MB42 at position 769 of the CDS causing a frameshift and introducing a stop codon. C, Detail of the C > T substitution in the genomic sequence of variant 2 isolates relative to isolate MB42 at position 916 of the CDS introducing a stop codon. D, Detail of the G > A substitution in the genomic sequence of the variant 5 isolate on the first base of the third intron as present in isolate MB42, which results in a loss of the splice site. The numbering above the alignment indicates the original position on SeMB42_scf158 as it is represented in reverse complement orientation. 


\section{Disruptive selection.}

After two multiplication rounds of pathotype 1(D1) isolate $01 \mathrm{WS}$ on the semisusceptible variety Erika, a pathotype $6(\mathrm{O} 1)$ phenotype was obtained for the resulting isolate E/II/2015 (van de Vossenberg et al. 2018). Both isolates 01WS and E/II/2015 were PacBio sequenced to determine whether a shift in the genetic population had resulted in the loss of the AvrSenl gene.

Almost all $(>99.9 \%)$ of the 20.986 PacBio CCS reads obtained for pathotype 1(D1) isolate 01WS represented the AvrSen 1 haplotype. The AvrSen 1 haplotype in E/II/2015 was almost completely lost, with only $0.7 \%$ of all 12,322 reads producing the wild-type sequence. The remaining $99.3 \%$ of the reads showed a $\mathrm{G}>\mathrm{A}$ substitution on position 29,183 of scaffold SeMB42_scf0158 (Supplementary Fig. S5). In the original 01WS isolate, seven CCS reads had the G > A substitution $(0.0003 \%)$ observed in E/II/2015. This substitution is positioned on the first base of the third intron and affects the GU dinucleotide of the third exon-intron boundary in the premRNA. The conserved GU dinucleotide is required for correct splicing of the premRNA and the $\mathrm{G}>\mathrm{A}$ substitution in the premRNA results in a loss of the splice site. As a consequence, a stop codon is introduced on position 94 of the amino acid sequence, resulting in a third truncated variant (avrSen1: $\mathrm{Asp}^{94}>$ stop $^{94}$ ) (i.e., variant 5) (Fig. 2).

\section{DISCUSSION}

Close to 40 different $S$. endobioticum pathotypes have been reported based on bioassays using a set of differentially resistant potato varieties. We hypothesized that the phenotypic differences between pathotypes are the result of different combinations of $R$ genes present in potato varieties and the presence or absence of their cognate $A v r$ genes in S. endobioticum isolates. At present, several QRLs providing resistance to $S$. endobioticum pathotypes have been described, of which two provide resistance specifically to pathotype 1(D1) isolates: Sen 1 and Sen 1-4. To identify the cognate Avr for the potato Sen1, which we refer to as AvrSen1, we exploited the recently assembled and annotated pathotype 1(D1) genome of isolate MB42 in combination with Illumina datasets generated for 30 isolates representing pathotypes that are of current importance in Europe or Canada.

\section{AvrSen1 identification strategy.}

Because potato varieties possessing the Senl locus are resistant to pathotype 1(D1) isolates but are susceptible to the "higher" pathotypes, we hypothesized that pathotype 1(D1) isolates possess the AvrSenl gene whereas higher pathotypes lost it on a functional or structural level. For the comparative genomic approach, two scenarios of loss of the AvrSenl gene were considered: mutations in the gene sequence leading to a loss of recognition due to the change in amino acid sequence of the AvrSen 1 protein, and (partial) deletion of the gene from the genome in higher pathotypes. We did not include criteria such as molecular weight, size, and cysteine richness, which have been attributed to be effector signatures (Sonah et al. 2016). Indeed, effectors frequently are reported to be cysteine rich and relatively small but large effector proteins have also been reported (Lo Presti et al. 2015). Also, selection for other effector signatures based on specific motifs-for example, the RxLR motif in oomycetes (Petre and Kamoun 2014) or Crinkler motifs, which were also found identified in the amphibian decline chytrid Batrachochytrium dendrobatidis (Rosenblum et al. 2012)—were not pursued in our approach.

Only five candidates were obtained from the presence-orabsence analysis, of which only one was predicted to be secreted. Manual verification showed that the gene models of the other candidates were correct and that these indeed did not belong to the secretome. Otherwise, manual verification was found to be essential to assess the reliability of read mapping
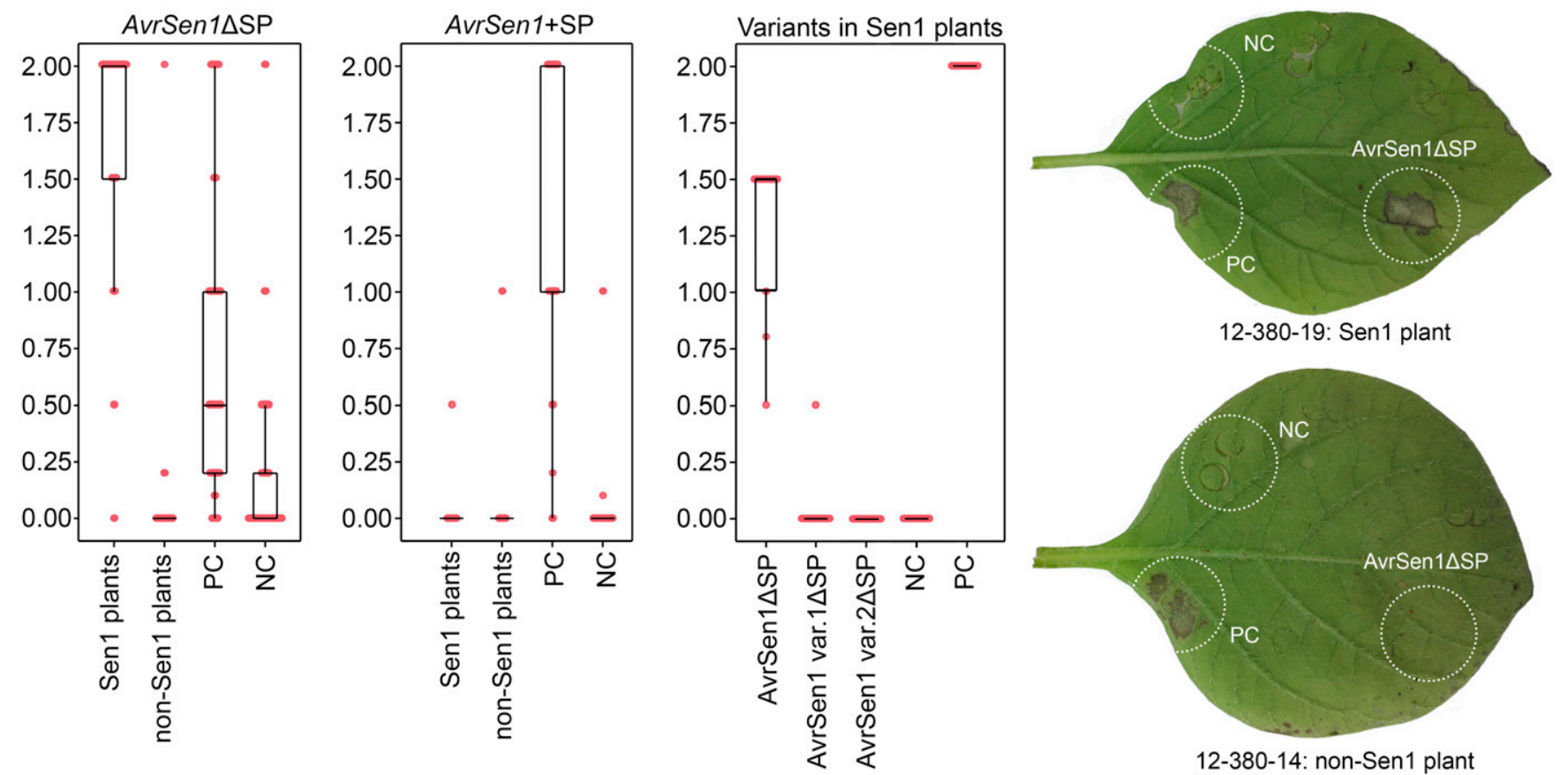

Fig. 3. Agroinfiltration of AvrSenl variants in potato plants. Boxplots of agroinfiltration scores obtained with constructs AvrSen1 $\Delta$ SP (left panel), in which Avr $8 / R 8$ coinfiltration served as positive control; AvrSen $1+\mathrm{SP}$ (center panel), in which Avr $8 / R 8$ coinfiltration served as positive control; and the truncated AvrSen 1 variants 1 and $2 \Delta \mathrm{SP}$ (right panel), in which AvrSen1 $\Delta$ SP and Avr8/R8 coinfiltration served as positive controls. The negative control consisted of $\beta$-glucuronidase (GUS) or $R 8$. Individual scores are represented as dots. Agroinfiltration results obtained in two progeny plants of the Aventra $\times$ Kuras population represent typical reactions observed for AvrSen1 $\mathrm{SP}$ in Sen1 containing plants (top leaf) and plants without Sen1 (bottom leaf). PC represents the positive control, which consisted of Avr8/R8 coinfiltration, and NC represents the negative control (GUS). 
and the resulting variant calling. Also, the significance of the $\mathrm{dN}$ changes were manually assessed with conservative $\mathrm{dN}$ changes, resulting in an amino acids with the same characteristics (e.g., Alanine to Valine), being regarded as insignificant because their influence to the tertiary structure of the protein was believed to be minimal. Notably, all SNPs observed in the AvrSenl gene of nonpathotype 1(D1) isolates led to the introduction of a stop codon, resulting in a truncated gene model.

Pathotype grouping of $S$. endobioticum isolates is based on tuber-based bioassays but agroinfiltration experiments are typically performed on leaves. We previously demonstrated that plant $R$ genes for the EPPO differential set (OEPP/EPPO 2017) were equally expressed in aboveground plant parts compared with the tuber-based assays (van de Vossenberg et al. 2019a). This justifies the use of the leaf-based agroinfiltration assay to test the interaction between candidate $A v r$ genes and $R$ genes.

\section{AvrSen1.}

Because the interaction between $S$. endobioticum and its host is specific, the AvrSenl gene was hypothesized to be present in the species-specific secretome. Indeed, the identified AvrSenI gene had no orthologs in the closely related species $S$. microbalum which has a nonpathogenic saprobic lifestyle.

Cartwright (1926) reported that, in incompatible interactions, zoospores encyst on the host cell and penetration occurs. Initially, the fungal thallus develops normally but, eventually, an immune response is triggered, resulting in localized cell death
(Cartwright 1926). This observation suggests that the strategy of overcoming pathogen- or microbe-associated molecular pattern-triggered immunity by $S$. endobioticum may be identical in the different pathotypes and that the differentiation between pathotypes is the result of effectors secreted in the cytoplasm after host penetration. The strong response of Sen1 plants to the cytoplasmic AvrSen $1 \Delta$ SP construct, and absence of a response when the AvrSenl was expressed with signal peptide, supports the intracellular recognition of the effector. Also, no nuclear localization signals, chloroplasts, or mitochondrial targeting peptides were present, suggesting that the protein is not sequestered to these organelles but is recognized upon intracellular secretion. Similar observations were made for the obligate biotrophic flax rust (Melampsora lini) effectors AvrM and AvrL567 (Catanzariti et al. 2006; Dodds et al. 2004). We hypothesize that also, in the case of wart resistance genes, nucleotide-binding site-leucine-rich repeat receptor (NLR) immune receptors are involved. In flax, it is the cytoplasmic NLR immune receptors that recognize the cognate $M$. lini Avr genes. Many of the described fungal Avr genes lack functional domains and have no predicted function (De Wit et al. 2009). Similarly, no Pfam domains, gene ontology terms, or protein family membership were predicted for AvrSen1, and its function in virulence remains elusive.

To date, two functionally annotated reference genomes of Synchytrium endobioticum are available: the Dutch MB42 pathotype 1(D1) and Canadian LEV6574 pathotype 6(O1) genomes (van de Vossenberg et al. 2019b). Both genomes were

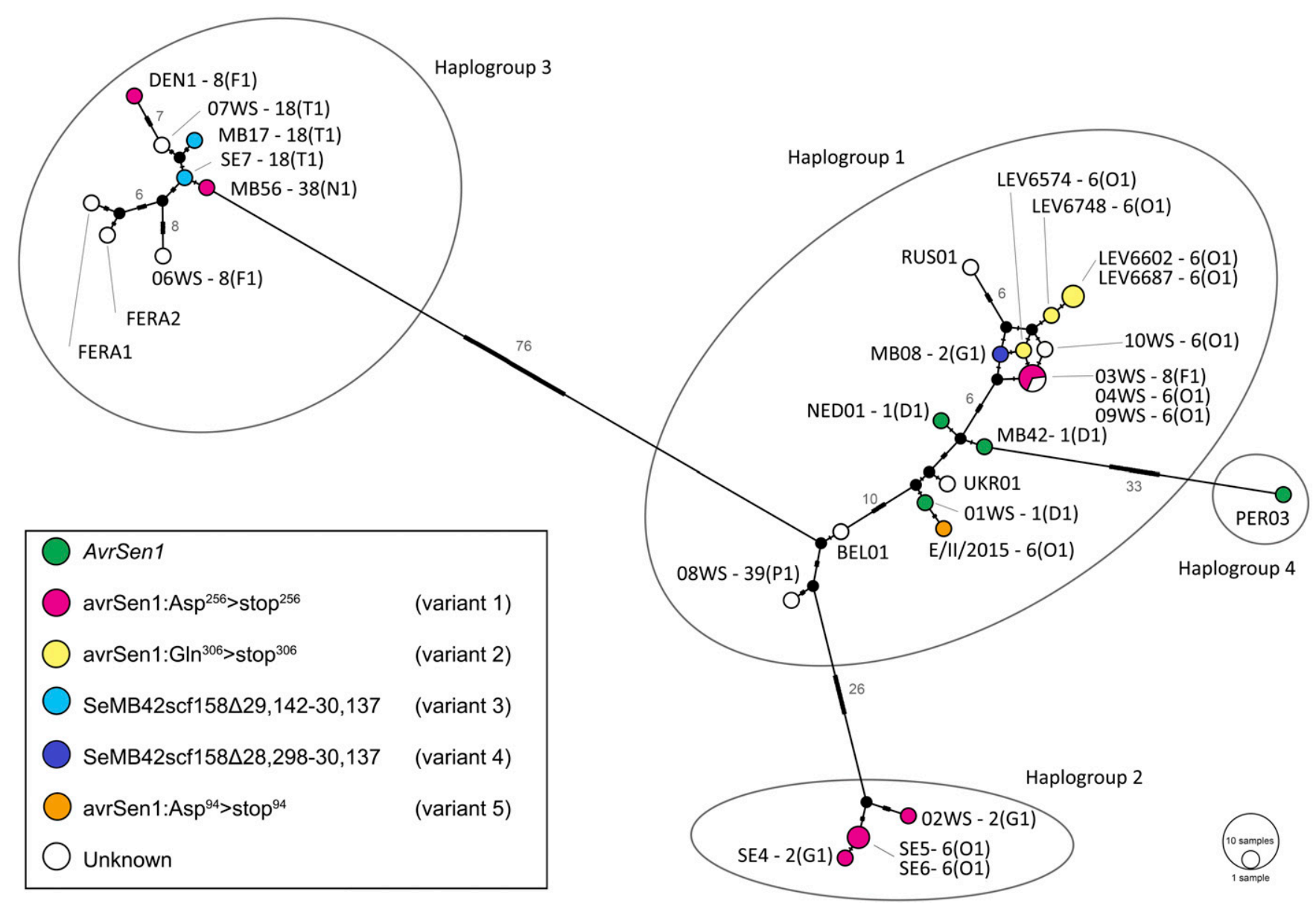

Fig. 4. Distribution of AvrSen1 and its variants among Synchytrium endobioticum isolates visualized in the mitochondrial haplotype network from van de Vossenberg et al. (2018). Colors represent the presence of AvrSen1 or its variants for a given isolate as identified from read mapping to the MB42 genome or through PacBio amplicon sequencing. Pathotype identities are shown when available. Black nodes represent hypothetical ancestors, and marks on the branches indicate the number of mutations, which are shown as numerical values on branches with $>5$ mutations. 
independently sequenced, assembled, and annotated, and the gene prediction in the LEV6574 genome reflects the truncated AvrSen1 variant 2 that was identified from the AvrSenl prediction pipeline. This indicates that not only is the particular SNP present in the Canadian genome but also the truncated gene model is expressed (Supplementary Fig. S6). In addition, the AvrSen1 variant 1 present in pathotype 2(G1) and 6(O1) isolates from haplogroup 2 was found to be expressed in planta. In plant parts infected with pathotype 18(T1) isolates, no transcripts for AvrSenl or its variants were identified, which corroborates the structural absence of the AvrSenl gene observed in pathotype 18(T1) isolates.

The AvrSenl gene (SeMB42_g04087 from the MB42 genome) has a single ortholog in the Canadian genome (i.e., SeLEV6574_g04683). Being a single-copy ortholog in both $S$. endobioticum isolates is atypical for an Avr gene because many effectors belong to multigene families and have diversified from a common ancestor (Lo Presti et al. 2015). In addition, the number of cysteine residues $(n=2)$ is lower and the protein length (376 amino acids) is larger compared with the features generally attributed to effector proteins. We would have not been able to detect the AvrSenl gene when applying these features as selection criteria, as was suggested by others (Sonah et al. 2016).

\section{AvrSen1 and its variants in S. endobioticum isolates.}

Five variants of the AvrSenl gene were identified, which suggests that the AvrSen 1 gene is under strong Senl selection pressure that is mainly exerted in potato cultivation. Indeed, Senl is widely deployed in current potato varieties (C. Prodhomme, unpublished). In contrast, $79 \%$ of all 8,031 S. endobioticum genes included in the screening for AvrSen 1 candidates do not display any $\mathrm{dN}$ changes or reduced gene coverage for any of the 14 isolates included in this study. A similar observation was made by Huang et al. (2014), who analyzed genetic variations of six $A v r$ genes in the rice blast fungus Magnaporthe oryzae, and compared these to seven randomly selected nonAvr control genes. In M. oryzae, Avr genes frequently show deletions and high levels of nucleotide variation leading to (shared) $\mathrm{dN}$ substitution in the diversified rice blast strains. Of the five AvrSenl variants, three are truncated gene models as the result of single-nucleotide insertions or substitutions. Similarly, in the oomycete $P$. infestans, a truncated version of the Avr4 protein remains unrecognized by plants with the $R 4$ gene (van Poppel et al. 2008).

Variant 1 (avrSen $1: \mathrm{Asp}^{256}>$ stop $^{256}$ ) was found most frequently in higher pathotypes representing different mitochondrial haplogroups, which are believed to have been independently introduced in Europe from the Andes (van de Vossenberg et al. 2018). Hence, it is likely that the mutation leading to avrSen1:Asp ${ }^{256}>$ stop $^{256}$ emerged early in the evolution and spread of the pathogen, which would suggest that the Sen1 locus should also be present in (wild) potato varieties in the native range of $S$. endobioticum. Variant 2 (avrSen1: $\mathrm{Gln}^{306}>$ stop $^{306}$ ) was found exclusively in the four Canadian pathotype 6(O1) isolates. S. endobioticum was introduced from Europe to Canada in the early 1900s to Newfoundland (Hampson 1993), from which it spread to Saint Edwards Island, where the sequenced isolates were obtained. The variant 2 haplotype was not found in the European isolates, which could be an effect of sampling or could indicate that the SNP leading to variant 2 is recent and occurred in the Canadian S. endobioticum isolates de novo. In South America, the presumed center of origin of potato, S. endobioticum interacts with many other Solanum spp. and their respective resistance genes. In this respect, it is interesting to note that the Peruvian isolate (PER03) has retained the intact AvrSenl.

\section{Disruptive selection.}

After two multiplications of pathotype 1(D1) isolate 01WS on potato cultivar Erika, which does not provide full resistance
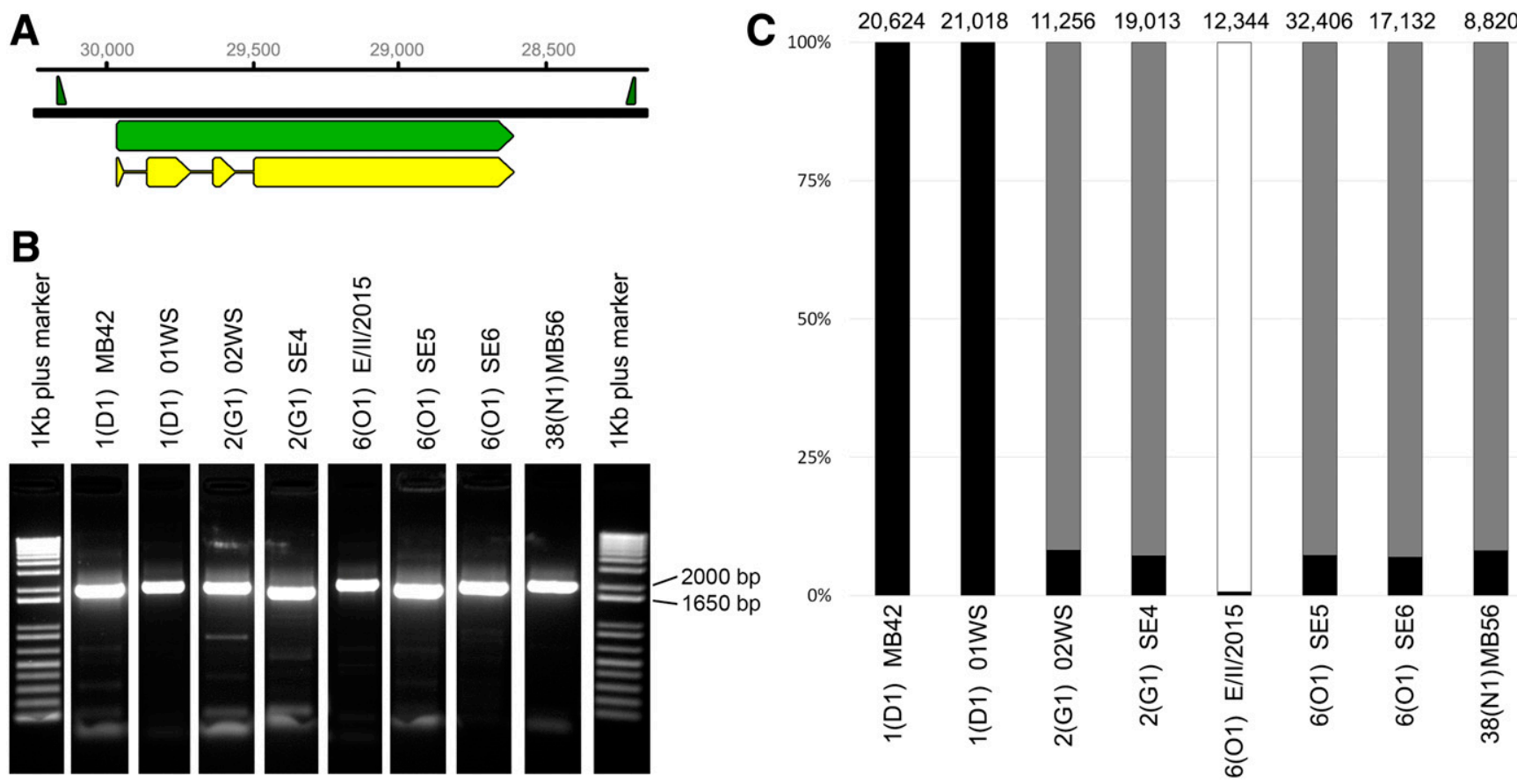

Fig. 5. AvrSenl amplicon sequencing with PacBio SMRT. A, Primer sites flanking the AvrSen1 gene resulting in a 1,983-nucleotide amplicon. Primers are annotated as green triangles, the AvrSenl gene sequence is annotated green, and the coding sequence is annotated in yellow. Numbers indicate the position of the gene on SeMB42_scf158, which is presented in reverse complement orientation to present the gene in 5' to $3^{\prime}$ direction. B, Amplicons obtained from selected isolates representing multiple pathotypes and mitochondrial haplogroups. The 1-kb-plus size marker was used for amplicon size estimation. C, Proportion of PacBio circular consensus sequence (CCS) reads representing AvrSenl (black), avrSenl variant 1 (gray), and avrSenl variant 5 (white). Numbers of PacBio CCS reads generated per sample are shown above the bars. 
to 1(D1), wart formation was obtained. The fungal isolate from the warted tissues (E/II/2015) was pathotyped, and produced a pathotype $6(\mathrm{O} 1)$ phenotype. This sample could be multiplied on (among other cultivars) Producent, which contains Sen1 (C. Prodhomme, unpublished). From the amplification of the AvrSenl gene followed by PacBio SMRT sequencing, we expected to observe a loss of the AvrSenl gene as a result of a selection for a loss-of-function mutation induced by the partially resistant Erika. Indeed, we observed a loss of AvrSen1 in isolate $\mathrm{E} / \mathrm{II} / 2015$ but, to our surprise, a novel variant was found: variant 5 .

Variant 5 is the result of a substitution on the first base of the third intron in the AvrSenl gene sequence. The first two bases of the exon-intron boundary are highly conserved and are required for splicing of the introns out of the premRNA (Roy and Irimia 2009). Polymorphisms in this sequence result in a readthrough of the third exon, resulting in the introduction of a stop codon at the 94th amino acid position. Low levels $(0.0006 \%)$ of the SNP leading to AvrSenl variant 5 in isolate $\mathrm{E} / \mathrm{II} / 2015$ were identified in isolate 01WS. However, at these low percentages, it is impossible to differentiate between sequence errors introduced by PacBio SMRT sequencing, errors introduced by amplification errors, or a true genotype. Nonetheless, the CCS reads with the variant 5 haplotype in isolate 01WS were of high quality and were built from 4 to 125 passages, with an average of 39 passages. Analysis of withinisolate diversity using mitochondrial haplotypes showed increased diversity in isolate $\mathrm{E} / \mathrm{II} / 2015$ relative to the original pathotype 1 (D1) isolate. Selection against the main genotype allowed proliferation of rare individuals (van de Vossenberg et al. 2018).

Whereas, in isolate E/II/2015, almost all AvrSen1 variation (99.3\% variant 5) was selected against low frequencies of the complete AvrSenl (7.0 to 8.2\%) and were identified in variant 1 isolates 02WS, MB56, SE4, SE5, and SE6. These variant 1 isolates were multiplied on the susceptible variety Deodara, which does not contain Sen1. AvrSen1 is found in most isolates tested, although sometimes in a minor haplotype. Both alleles could be maintained in the population on account of balancing selection, and have a positive effect on the overall fitness of the population.

The observed within-isolate variation, with low levels of the avirulent allele being present, could explain the escapes in susceptible pathogen-host interactions which have been reported in S. endobioticum bioassays (Hampson 1992). This is further supported by the observation that, in an S. endobioticum bioassay, both wart formation and an HR can be observed on different shoots of the same tuber.

\section{Closing remarks and outlook.}

Here, we report the identification of the first $A v r$ gene in the division Chytridiomycota, which demonstrates that the genefor-gene model applies to the potato-S. endobioticum pathosystem. Our strategy proved to be effective in identifying the AvrSen 1 gene, and a similar approach may result in uncovering more Avr genes. This is particularly true when it is specifically matched to QRL- or $R$ gene-based predicted absences and presences. AvrSen 1 could also be instrumental in finding Avr genes in other chytrid pathogens such as $B$. dendrobatidis, and may also help to identify the potato Sen 1 gene.

The AvrSenl gene is under strong selective pressure, and several forms of loss of the AvrSenl locus were observed. Given the broad presence of variant 1 and, to a lesser extent, variant 2 in nonpathotype 1(D1) isolates, these could potentially be recognized by other $R$ genes, making them Avr factors. Because most mutations resulted in a C-terminal truncation, this suggests that this part is essential for recognition by Sen1.
Additional research is required to show which part of AvrSen 1 is indeed recognized.

We previously observed that pathotype $2(\mathrm{G} 1)$ and $6(\mathrm{O} 1)$ isolates that produced the same phenotype were present in different mitochondrial haplogroups (van de Vossenberg et al. 2018), and concluded that these phenotypes could have emerged independently from different genetic backgrounds. Our results regarding the different types of loss of AvrSenl in the pathotype $2(\mathrm{G} 1)$ and $6(\mathrm{O} 1)$ isolates further strengthens this hypothesis (Fig. 4). Additionally, when regarding all speciesspecific secreted proteins as potential effectors, different patterns of predicted loss of function can be seen between the two pathotype 2(G1) isolates and the Canadian and European pathotype 6(O1) isolates. This analysis also allows further differentiation between the two pathotype 1(D1) isolates (Supplementary Fig. S7). These different types of pathotypes 2(G1) and 6(O1) could have evolved their own set of Avr genes which are not detected in the current pathotyping methods because the cognate $R$ genes are not included in the differential potato panel. The AvrSenl gene can be used to screen isolates to identify these possible different genotypes in isolates phenotypically identified as pathotype 1(D1). In time, functional markers such as the AvrSenl can contribute to alternative pathotyping assays.

\section{MATERIALS AND METHODS}

\section{Identification of AvrSen1 candidates.}

Whole-genome sequence data used in this study were generated by van de Vossenberg et al. (2018) and were obtained from resting spores extracted from fresh warts. These datasets comprised 30 isolates that were grouped into seven different pathotypes. Datasets with $>10 \times$ median coverage and known pathotype identity were included in this study. Sequence reads were mapped (length fraction: 0.8, similarity fraction: 0.9) to the $S$. endobioticum pathotype 1(D1) isolate MB42 reference genome (van de Vossenberg et al. 2019b) in CLC Genomics Workbench v11.0.1 (Qiagen), and mappings were improved with the local realignment tool (default settings) to better resolve the mapping in areas around insertions and deletions.

To determine putative amino acid sequence polymorphisms in different isolates, variants were called using the basic variant detection tool (minimum coverage $=5$, minimum count $=3$, minimum frequency $=70 \%$, and broken reads $=$ ignore), and $\mathrm{dN}$ changes were identified with the Amino Acid Changes tool. Using this tool, the number of $\mathrm{dN}$ changes relative to the MB42 genome were determined per gene for each of the isolates tested. Genes with one or more $\mathrm{dN}$ changes in an isolate were regarded to be putatively functionally absent (i.e., loss of function). To determine (partial) deletions of genes in different isolates, the percentage of length coverage relative to the MB42 reference genome was determined. Per mapped isolate, a consensus sequence was created for each gene, and the number of nucleotides with no coverage was determined. Genes with $<90 \%$ coverage in an isolate were considered to be putatively structurally absent. Genes present in pathotype 1(D1) isolates but absent in higher pathotypes were regarded as candidate AvrSenl genes.

These candidate genes were individually inspected to verify whether they were legitimate candidates by determining (i) correctness of gene prediction by checking the MB42 RNAseq (van de Vossenberg et al. 2019b) read mapping to the MB42 reference genome, (ii) significance of $\mathrm{dN}$ change and variants present in other pathotypes by differentiating between conservative and nonconservative $\mathrm{dN}$ changes, (iii) significance of $<90 \%$ length coverage, and (iv) functional predictions with InterProScan. Presence of nuclear localization signals, chloroplasts, or 
mitochondrial targeting peptides in AvrSen1 were determined with LOCALIZER v1.0.4 (Sperschneider et al. 2017). A graphical summary of the detection pipeline is presented in Figure 1.

\section{The $S$. endobioticum-specific secretome.}

The secretome was defined as proteins possessing a secretion signal as predicted with SignalP v4.1 (Petersen et al. 2011), absence of a mitochondrial targeting peptide as determined with TargetP v1.1 (Emanuelsson et al. 2000), and absence of transmembrane helices or GPI anchors as determined with TMHMM v2.0 (Krogh et al. 2001) and PredGPI (Pierleoni et al. 2008), respectively. Next, OrthoFinder v1.1.4 (Emms and Kelly 2015) output generated by van de Vossenberg et al. (2019b) was used to identify $S$. endobioticum-specific genes. In short, protein sequences of the $S$. endobioticum pathotype 1(D1) MB42 and pathotype 6(O1) LEV6574 reference genomes were compared with the proteomes of nine other chytrid isolates, including the closely related saprobic $S$. microbalum and the more distant amphibian decline pathogen $B$. dendrobatidis. From this analysis, orthologous groups unique to both $S$. endobioticum isolates or isolate MB42 were regarded $S$. endobioticum or pathotype 1(D1) specific.

\section{Cloning of AvrSen1 candidates and variants.}

CDSs of the AvrSen 1 candidate and its truncated variants were synthesized by GenScript after codon optimization for plants and removal of BsaI, BpiI, and BsmBI restriction sites. Gene expression constructs were prepared with the Golden Gate Cloning system and contained the AvrSen1, avrSen1:Asp ${ }^{256}>$ stop $^{256}$, and avrSen $1: \mathrm{Gln}^{306}>$ stop $^{306}$ CDSs inserted between the Cauliflower mosaic virus (CaMV) plCSL13001 promotor $+5^{\prime}$ untranslated region (UTR) and the CaMV plCH41414 3'UTR + terminator sequences (Engler et al. 2014) in a modified pBINPLUS binary vector (pBINPLUS-GG). AvrSen 1 constructs were prepared with and without the Nicotiana benthamiana CRT (calreticulin) signal peptide plCH37326 to test for differential apoplastic or cytoplasmic recognition. The correctness of the constructs was verified using Sanger sequencing. pBINPLUS-GG plasmids with AvrSenl inserts were transformed to Agrobacterium tumefaciens strain AGL + VirG (van der Fits et al. 2000) using electroporation. The presence of the intact plasmid was confirmed using PCR, before using the transformed colonies for agroinfiltration.

\section{Agroinfiltration.}

The verified AvrSenl candidate and two of the functional variants were cloned and transiently expressed in potato leaves to determine whether their gene products were recognized by Sen1. Progeny from crosses between the pathotype 1(D1) resistant varieties Desiree and Kuras and the pathotype 1(D1) susceptible variety Aventra were selected (C. Prodhomme, unpublished) based on their resistance or susceptibility to S. endobioticum pathotype 1(D1), on the presence or absence of Sen1, and on their competence for transient expression.

All progeny clones and the parent varieties were field propagated to provide tubers. In 2016, six and eight tubers were tested for pathotype 1(D1) resistance using the GlynneLemmerzahl and Spieckermann bioassays, respectively (OEPP/EPPO 2004). A subset of clones and the parents were rephenotyped in 2017 with 6 and 12 tubers, respectively. Presence or absence of Senl was determined using five Kompetitive allele-specific PCR markers specific to the Senl haplotype (C. Prodhomme, unpublished). The progeny clones were grown in vitro and tested for agrocompetence with $A$. tumefaciens suspensions at an optical density (OD) if 0.3 and 0.1. A positive control consisting of the coinfiltration of the $P$. infestans Avr8 gene and the cognate $R 8$ gene [38]) and a negative control ( $\beta$-glucuronidase [GUS]) were used in this experiment. Noncompetent lines which showed aspecific reactions to A. tumefaciens or did not show any HR when infiltrated with the positive control were excluded.

The transformed colonies were cultured in $5 \mathrm{ml}$ of LuriaBertani (LB) medium containing the appropriate antibiotics and grown overnight $\left(28\right.$ to $30^{\circ} \mathrm{C}$, with shaking at $\left.200 \mathrm{rpm}\right)$. Between 20 and $200 \mu \mathrm{l}$ of the LB cultures was diluted in $15 \mathrm{ml}$ of yeast extract broth (YEB) medium containing the appropriate antibiotics, $1.5 \mu \mathrm{l}$ of acetosyringone $(200 \mathrm{mM})$, and $150 \mu \mathrm{l}$ of 2(N-morpholino)-ethane sulfonic acid $(1 \mathrm{M})$ and grown overnight $\left(28\right.$ to $30^{\circ} \mathrm{C}$, with shaking at $\left.200 \mathrm{rpm}\right)$. The YEB cultures were centrifuged for $10 \mathrm{~min}$ at $4,000 \times g$. The supernatant was poured off and the pellet was carefully resuspended until the appropriate OD in freshly made MMA (2\% sucrose, $0,5 \% \mathrm{MS}$ salts without vitamins, $10 \mathrm{mM} \mathrm{MES}, \mathrm{pH}=5.5$ ) containing 0.2 $\mathrm{mM}$ acetosyringone. The cultures were incubated 1 to $3 \mathrm{~h}$ before infiltrations at room temperature in the dark.

Potato plants were clonally propagated from in vitro culture on Murashige and Skoogs medium supplemented with 2\% sucrose. Two weeks after incubation at $25^{\circ} \mathrm{C}$, the rooted cuttings were transferred to the greenhouse in $11-\mathrm{cm}$ pots with potting soil under greenhouse conditions (constant 18 to $21^{\circ} \mathrm{C}$ and $90 \%$ relative humidity with a light regime of $16 \mathrm{~h}$ of light and $8 \mathrm{~h}$ of darkness). Using a syringe, small amounts of bacterial suspensions (OD of 0.3 or 0.1 ) containing the pBINPLUS-GG with inserts of interest were injected on the abaxial side of selected leaves at 3 to 4 weeks after planting in the greenhouse. Each genotype was tested in duplicate and three leaves per plant were injected, referred to as "low", "middle", and "high" based on their relative position on the plant. On each leaf, a positive control (Avr8/R8 coinfiltration) (Vossen et al. 2016); a negative control (GUS or $R 8$ gene) was included to monitor the effectiveness of the agroinfiltration experiments. After injection, plants were kept in the greenhouse for 2 to 5 days before scoring HR reactions following Rietman et al. (2012). Briefly, the scoring scale describes the part of the infiltrated zone that shows HR and ranges from 0 to 2 . Score $0=$ no cell death visible, score 1 = half of the infiltrated zone shows cell death, and score $2=100 \%$ of the infiltrated zone shows HR.

\section{AvrSen1 and its variants in S. endobioticum isolates.}

The presence of functional AvrSenl genes in sequenced isolates was superimposed to the $S$. endobioticum haplotype network as described by van de Vossenberg et al. (2018), which was based on complete mitochondrial genomes. Isolates in the network were colored according to presence of AvrSenl or its functional variants, which was based on the Illumina read mappings of 30 isolates (identification of AvrSen1 candidates) and PacBio SMRT sequencing of AvrSen1 amplicons (see below). Expression of AvrSenl and its variants in planta was determined by mapping publicly available RNAseq data obtained from infected plant parts (Busse et al. 2017; van de Vossenberg et al. 2019a). Busse et al. (2017) generated RNAseq data from fresh tuber warts induced by a pathotype 18(T1) isolate of the pathogen (SRA: SRP056765), and van de Vossenberg et al. (2019a) generated RNAseq data from warted aboveground potato plant parts (variety Deodara) inoculated with pathotypes 1(D1), 2(G1), 6(O1), and 18(T1) (SRA: ERX3121142 to ERX3121155). Reads were mapped to the MB42 reference genome in CLC using the RNAseq analysis tool $($ length fraction $=0.8$ and similarity fraction $=0.8$ ).

\section{Cooccurrence of AvrSen1 and its variants within $S$. endobioticum isolates.}

Because $S$. endobioticum isolates may contain a population of genotypes (van de Vossenberg et al. 2018), and we observed 
allelic variation for AvrSenl in the Illumina sequences derived from a single isolate, we assessed the variation of AvrSenl within isolates by next-generation sequencing of AvrSenl amplicons. Isolates used by van de Vossenberg et al. (2018) representing different pathotypes and mitochondrial haplogroups were selected for the analysis, including the German pathotype 1(D1) isolate 01WS and laboratory isolate E/II/2015 (Supplementary Table S2). The latter isolate was produced after two multiplications of $01 \mathrm{WS}$ on the semiresistant variety Erika, after which it showed a pathotype 6(O1)-like phenotype.

Primers were designed allowing generic amplification of the AvrSen1 locus (Supplementary Fig. S2). Amplification of AvrSenl gene was performed in $20-\mu 1$ reaction mixes based on the Takara Premix HotStart (TaKaRa) reagents containing 500 nM tagged AvrSen1_fw (tag-5' -CTG GAA GCT CTA TTT CAT AGG TCA-3') primer, $500 \mathrm{nM}$ tagged AvrSen1_rv (tag5'-CAC TCA CTC GTG CCA TTT CTA-3') primer, and $2 \mu \mathrm{l}$ of target DNA. PCR thermocycler conditions were as follows: 2 min of initial denaturation at $94^{\circ} \mathrm{C}$; followed by 35 cycles of $30 \mathrm{~s}$ at $94^{\circ} \mathrm{C}, 30 \mathrm{~s}$ at $55^{\circ} \mathrm{C}$, and $2 \mathrm{~min}$ at $72^{\circ} \mathrm{C}$; and with a final elongation of $5 \mathrm{~min}$ at $72^{\circ} \mathrm{C}$. Amplification primers were tagged to create sample-specific combinations allowing selection of isolate-specific sequence data on the pooled amplicons. Amplicons were pooled in equimolar amounts and subjected to PacBio SMRT sequencing. From the raw PacBio sequence data, CCS were generated and CCS data were successively binned based on their sample-specific tags using a custom script (WUR git server; Wageningen University \& Research). Sample-specific CCS data were mapped to the AvrSenl gene in Geneious Prime (Kearse et al. 2012) (Biomatters Limited) using a reference assembly with default settings. Next, variants were detected and quantified with the Find Variations/SNPs tool (minimum variant frequency $=0.1$ and maximum variant $P$ value $=10^{-4}$ )

\section{ACKNOWLEDGMENTS}

We thank Averis Seeds BV, Böhm-Nordkartoffel Agrarproduktion GmbH \& Co. OHG, Danespo, HZPC Holland BV, C. Meijer BV, SaKa Pflanzenzucht $\mathrm{GmbH} \& \mathrm{Co}$. KG, and Teagasc for funding, biological material, and stimulating scientific discussions.

\section{AUTHOR-RECOMMENDED INTERNET RESOURCE}

Topsector: https://topsectortu.nl/nl/integrated-genomics-and-effectoromicsimpulse-potato-wart-resistance-management-and-breeding

\section{LITERATURE CITED}

Asai, S., and Shirasu, K. 2015. Plant cells under siege: Plant immune system versus pathogen effectors. Curr. Opin. Plant Biol. 28:1-8.

Baayen, R. P., Cochius, G., Hendriks, H., Meffert, J. P., Bakker, J., Bekker, M., van den Boogert, P. H. J. F., Stachewicz, H., and van Leeuwen, G. C. M. 2006. History of potato wart disease in Europe-A proposal for harmonisation in defining pathotypes. Eur. J. Plant Pathol. 116:21-31.

Barr, D. J. S. 2001. Chytridiomycota. Pages 93-112 in: Systematics and Evolution: Part A. Springer, Berlin, Heidelberg.

Braun, H. C. 1942. Biologische Spezialisierung bei Synchytrium endobioticum (Schilb.). Z. Pflanzenkrankh. (Pflanzenpathol.) Pflanzenschutz 52: 481-486.

Brown, J. K., and Tellier, A. 2011. Plant-parasite coevolution: Bridging the gap between genetics and ecology. Annu. Rev. Phytopathol. 49: 345-367.

Brugmans, B., Hutten, R. G., Rookmaker, A. N., Visser, R. G., and van Eck, H. J. 2006. Exploitation of a marker dense linkage map of potato for positional cloning of a wart disease resistance gene. Theor. Appl. Genet. 112:269-277.

Busse, F., Bartkiewicz, A., Terefe-Ayana, D., Niepold, F., Schleusner, Y., Flath, K., Sommerfeldt-Impe, N., Lübeck, J., Strahwald, J., Tacke, E., Hofferbert, H. R., Linde, M., Przetakiewicz, J., and Debener, T. 2017. Genomic and transcriptomic resources for marker development in
Synchytrium endobioticum, an elusive but severe potato pathogen Phytopathology 107:322-328.

Cartwright, K. 1926. On the nature of the resistance of the potato to wart disease. Ann. Bot. (London, U.K.) os-40:391-395.

Catanzariti, A.-M., Dodds, P. N., Lawrence, G. J., Ayliffe, M. A., and Ellis, J. G. 2006. Haustorially expressed secreted proteins from flax rust are highly enriched for avirulence elicitors. Plant Cell 18:243-256.

Cook, D. E., Mesarich, C. H., and Thomma, B. P. H. J. 2015. Understanding plant immunity as a surveillance system to detect invasion. Annu. Rev. Phytopathol. 53:541-563.

Curtis, K. M. 1921. IX.-The life-history and cytology of Synchytrium endobioticum (Schilb.), Perc., the cause of wart disease in potato. Philos. Trans. R. Soc. B 210:409-478.

Dawkins, R., Krebs, J. R., Maynard Smith, J., and Holliday, R. 1979. Arms races between and within species. Proc. R. Soc. B 205:489-511.

De Wit, P. J. G. M., Mehrabi, R., Van den Burg, H. A., and Stergiopoulos, I. 2009. Fungal effector proteins: Past, present and future. Mol. Plant Pathol. 10:735-747.

Dodds, P. N., Lawrence, G. J., Catanzariti, A.-M., Ayliffe, M. A., and Ellis, J. G. 2004. The Melampsora lini AvrL567 avirulence genes are expressed in haustoria and their products are recognized inside plant cells. Plant Cell 16:755-768.

Emanuelsson, O., Nielsen, H., Brunak, S., and von Heijne, G. 2000 Predicting subcellular localization of proteins based on their N-terminal amino acid sequence. J. Mol. Biol. 300:1005-1016.

Emms, D. M., and Kelly, S. 2015. OrthoFinder: Solving fundamental biases in whole genome comparisons dramatically improves orthogroup inference accuracy. Genome Biol. 16: Article 157.

Engler, C., Youles, M., Gruetzner, R., Ehnert, T.-M., Werner, S., Jones, J. D. G., Patron, N. J., and Marillonnet, S. 2014. A golden gate modular cloning toolbox for plants. ACS Synth. Biol. 3:839-843.

EPPO. 2018. European and Mediterranean Plant Protection Organization (EPPO) global database. https://gd.eppo.int/

Flor, H. H. 1971. Current status of the gene-for-gene concept. Annu. Rev. Phytopathol. 9:275-296.

Hampson, M. C. 1988. Control of potato wart disease through the application of chemical soil treatments: A historical review of early studies (1909-1928). Bull. OEPP/EPPO Bull. 18:153-161.

Hampson, M. C. 1992. A bioassay for Synchytrium endobioticum using micropropagated potato plantlets. Can. J. Plant Pathol. 14:289-292.

Hampson, M. C. 1993. History, biology and control of potato wart disease in Canada. Can. J. Plant Pathol. 15:223-244.

Haverkort, A. J., Boonekamp, P. M., Hutten, R., Jacobsen, E., Lotz, L. A. P., Kessel, G. J. T., Vossen, J. H., and Visser, R. G. F. 2016. Durable late blight resistance in potato through dynamic varieties obtained by cisgenesis: Scientific and societal advances in the DuRPh project. Potato Res. 59:35-66.

Heckman, D. S., Geiser, D. M., Eidell, B. R., Stauffer, R. L., Kardos, N. L., and Hedges, S. B. 2001. Molecular evidence for the early colonization of land by fungi and plants. Science 293:1129-1133.

Hehl, R., Faurie, E., Hesselbach, J., Salamini, F., Whitham, S., Baker, B., and Gebhardt, C. 1999. TMV resistance gene $\mathrm{N}$ homologues are linked to Synchytrium endobioticum resistance in potato. Theor. Appl. Genet. 98:379-386.

Huang, J., Si, W., Deng, Q., Li, P., and Yang, S. 2014. Rapid evolution of avirulence genes in rice blast fungus Magnaporthe oryzae. BMC Genet. $15: 45$.

Karling, J. S. 1964. Synchytrium. Academic Press, New York, NY, U.S.A. Kearse, M., Moir, R., Wilson, A., Stones-Havas, S., Cheung, M., Sturrock, S., Buxton, S., Cooper, A., Markowitz, S., Duran, C., Thierer, T., Ashton, B., Meintjes, P., and Drummond, A. 2012. Geneious Basic: An integrated and extendable desktop software platform for the organization and analysis of sequence data. Bioinformatics 28:1647-1649.

Krogh, A., Larsson, B., von Heijne, G., and Sonnhammer, E. L. 2001. Predicting transmembrane protein topology with a hidden Markov model: Application to complete genomes. J. Mol. Biol. 305:567-580.

Lange, L., and Olson, L. W. 1981a. Development of the resting sporangia of Synchytrium endobioticum, the causal agent of potato wart disease. Protoplasma 106:83-95.

Lange, L., and Olson, L. W. 1981b. Development of the zoosporangia of Synchytrium endobioticum, the causal agent of potato wart disease. Protoplasma 106:97-108.

Lo Presti, L., Lanver, D., Schweizer, G., Tanaka, S., Liang, L., Tollot, M., Zuccaro, A., Reissmann, S., and Kahmann, R. 2015. Fungal effectors and plant susceptibility. Annu. Rev. Plant Biol. 66:513-545.

Obidiegwu, J. E., Flath, K., and Gebhardt, C. 2014. Managing potato wart: A review of present research status and future perspective. Theor. Appl Genet. 127:763-780. 
OEPP/EPPO. 2004. PM 7/28 (1) Synchytrium endobioticum. Bull. OEPP/EPPO Bull. 34:213-218.

OEPP/EPPO. 2017. PM 7/28 (2) Synchytrium endobioticum. Bull. OEPP/EPPO Bull. 47:420-440.

Petersen, T. N., Brunak, S., von Heijne, G., and Nielsen, H. 2011. SignalP 4.0: Discriminating signal peptides from transmembrane regions. Nat. Methods 8:785-786.

Petre, B., and Kamoun, S. 2014. How do filamentous pathogens deliver effector proteins into plant cells? PLoS Biol. 12:e1001801.

Pierleoni, A., Martelli, P. L., and Casadio, R. 2008. PredGPI: A GPI-anchor predictor. BMC Bioinformatics 9:392.

Plich, J., Przetakiewicz, J., Śliwka, J., Flis, B., Wasilewicz-Flis, I., and Zimnoch-Guzowska, E. 2018. Novel gene Sen2 conferring broadspectrum resistance to Synchytrium endobioticum mapped to potato chromosome XI. Theor. Appl. Genet. 131:2321-2331.

Prodhomme, C., Esselink, D., Borm, T., Visser, R. G. F., van Eck, H. J., and Vossen, J. H. 2019. Comparative subsequence sets analysis (CoSSA) is a robust approach to identify haplotype specific SNPs; mapping and pedigree analysis of a potato wart disease resistance gene Sen3. Plant Methods 15: Article 60.

Przetakiewicz, J. 2015. The viability of winter sporangia of Synchytrium endobioticum (Schilb.) Perc. from Poland. Am. J. Potato Res. 92: 704-708.

Rietman, H., Bijsterbosch, G., Cano, L. M., Lee, H. R., Vossen, J. H., Jacobsen, E., Visser, R. G., Kamoun, S., and Vleeshouwers, V. G. 2012. Qualitative and quantitative late blight resistance in the potato cultivar Sarpo Mira is determined by the perception of five distinct RXLR effectors. Mol. Plant-Microbe Interact. 25:910-919.

Rosenblum, E. B., Poorten, T. J., Joneson, S., and Settles, M. 2012. Substrate-specific gene expression in Batrachochytrium dendrobatidis, the chytrid pathogen of amphibians. PLoS One 7:e49924.

Roy, S. W., and Irimia, M. 2009. Splicing in the eukaryotic ancestor: Form, function and dysfunction. Trends Ecol. Evol. 24:447-455.

Schilberszky, K. 1896. Ein neuer Schorfparasit der Kartoffelknollen. Ber. Dtsch. Bot. Ges. 14:36-37.

Sonah, H., Deshmukh, R. K., and Bélanger, R. R. 2016. Computational prediction of effector proteins in fungi: Opportunities and challenges. Front. Plant Sci. 7:126.

Sperschneider, J., Catanzariti, A.-M., DeBoer, K., Petre, B., Gardiner, D. M., Singh, K. B., Dodds, P. N., and Taylor, J. M. 2017. LOCALIZER:
Subcellular localization prediction of both plant and effector proteins in the plant cell. Sci. Rep. 7: Article 44598.

USDA CDC. 2018. Federal Select Agent Program, Select Agents and Toxins List. United States Department of Agriculture and Centers for Disease Control and Prevention. https://www.selectagents.gov/SelectAgents andToxinsList.html

van de Vossenberg, B. T. L. H., Brankovics, B., Nguyen, H. D. T., van GentPelzer, M. P. E., Smith, D., Dadej, K., Przetakiewicz, J., Kreuze, J. F. Boerma, M., van Leeuwen, G. C. M., André Lévesque, C., and van der Lee, T. A. J. 2018. The linear mitochondrial genome of the quarantine chytrid Synchytrium endobioticum; insights into the evolution and recent history of an obligate biotrophic plant pathogen. BMC Evol. Biol. 18: Article 136.

van de Vossenberg, B. T. L. H., van Gent-Pelzer, M. P. E., Boerma, M., van der Gouw, L. P., van der Lee, T. A. J., and Vossen, J. H. 2019a. An alternative bioassay for Synchytrium endobioticum demonstrates the expression of potato wart resistance in aboveground plant parts. Phytopathology 109:1043-1052.

van de Vossenberg, B. T. L. H., Warris, S., Nguyen, H. D. T., van GentPelzer, M. P. E., Joly, D. L., van de Geest, H. C., Bonants, P. J. M., Smith, D. S., Lévesque, C. A., and van der Lee, T. A. J. 2019b. Comparative genomics of chytrid fungi reveal insights into the obligate biotrophic and pathogenic lifestyle of Synchytrium endobioticum. Sci. Rep. 9: Article 8672.

van der Fits, L., Deakin, E. A., Hoge, J. H., and Memelink, J. 2000. The ternary transformation system: Constitutive virG on a compatible plasmid dramatically increases Agrobacterium-mediated plant transformation. Plant Mol. Biol. 43:495-502.

van Poppel, P. M., Guo, J., van de Vondervoort, P. J., Jung, M. W., Birch, P. R., Whisson, S. C., and Govers, F. 2008. The Phytophthora infestans avirulence gene Avr4 encodes an RXLR-dEER effector. Mol. PlantMicrobe Interact. 21:1460-1470.

Vossen, J. H., van Arkel, G., Bergervoet, M., Jo, K. R., Jacobsen, E., and Visser, R. G. 2016. The Solanum demissum R8 late blight resistance gene is an $\mathrm{Sw}-5$ homologue that has been deployed worldwide in late blight resistant varieties. Theor. Appl. Genet. 129: 1785-1796.

Wang, Y., and Wang, Y. 2018. Trick or treat: Microbial pathogens evolved apoplastic effectors modulating plant susceptibility to infection. Mol. Plant-Microbe Interact. 31:6-12. 